\title{
Addressing a Northern Food Crisis: Process Evaluation of Nutrition North Canada
}

\author{
Lauren Achtemichuk *
}

\begin{abstract}
Inflated food costs are a contributing factor to food insecurity in isolated communities of Canada's North. To increase the affordability and accessibility of healthy food in Northern communities, a federal government program Nutrition North Canada (NNC) offers retail-based subsidies on select nutritious foods shipped by air. In this paper, I integrate methods of process evaluation to determine whether or not the program components of NNC, such as the defined target population and subsidy design, are sufficient to achieve the intended program outcomes of increased affordability and accessibility of nutritious foods. A literature review drawing on government documents and journal articles outlines the setting of northern food insecurity and defines an inventory of NNC program components. Media articles published between 2011 and 2015 provide context and draw focus to specific implementation issues drawn from the NNC program. The process evaluation for this paper examines these documents for examples of inconsistency within the NNC program's target, design, and structure that will affect successful program implementation and delivery. My results focus on inadequacies in the structure of the community eligibility target, subsidy design, and compliance reports. I conclude with recommendations on revising and strengthening these components, to ensure that the Nutrition North Canada program can reach its key goal of increasing the affordability and accessibility of healthy foods in isolated northern communities that do not have year-round marine and/or ground transport.
\end{abstract}

Keywords: Nutrition North Canada, food insecurity, Northern communities, process evaluation

Healthy food is integral to health, culture, and wellbeing. However, access to healthy food is not evenly distributed across communities in Canada. Fuel costs and limited transportation contribute to increased food prices in northern parts of Canada. Higher food costs result in food insecurity if people are unable to afford adequate food on a daily basis to meet their nutritional needs. High levels of food insecurity in Canada's North largely stem from the quick transition of Aboriginal communities from traditional subsistence lifestyles to participation in sedentary wageeconomies (Standing Committee on Aboriginal Affairs and Northern Development [SCAAND], 2011). Traditional hunting grounds are difficult to access without boats or snowmobiles, while hunting equipment and fuel are expensive to purchase. Most people rely on market foods for the majority of their food intake, but the prices of these

\footnotetext{
*Department of Enviroment \& Society, College of Arts and Science, University of Saskatchewan, Saskatoon, SK, Canada

Correspondence: lauren.achtemichuk@usask.ca

University of Saskatchewan Undergraduate Research Journal Volume 2, Issue 2, 2016
} 
items are inflated due to the high costs associated with transportation and shipping to isolated communities.

In order to reduce high costs of food within communities in the Canadian territories or northern parts of most provinces, the federal government subsidizes food costs through a program redesigned in 2011, called Nutrition North Canada (NNC). NNC is a retail subsidy program that aims to make perishable, nutritious food more accessible and affordable to residents in isolated Northern communities that do not have year-round marine or ground transport. This paper carries out a process evaluation on NNC, to determine whether or not it has the capacity and design to improve food security in Canada's North.

\section{Methods}

For this article, I conducted a process evaluation to determine potential gaps in the program design that inhibit the NNC program from reaching its goals. Process evaluations examine factors such as the program origins, program structure, components and delivery system, perceptions of program participants, and resources used for program operation to assess if the program is capable of achieving the intended outcomes (Dehar, Casswell, \& Duignan, 1993). This type of approach moves away from the common evaluation approach of identifying program outputs and impacts, known as a 'black box' method (Harachi, Abbott, Catalano, Haggerty, \& Fleming, 1999). The black box approach fails to establish a causal relationship between program outputs and outcomes, meaning its evaluations are of limited value for improving the delivery of services. As the intention of this paper is to generate recommendations, a process evaluation is a legitimate methodological choice.

To conduct the process evaluation, I analyzed and reviewed government documents, Auditor General reports, journal and media articles. Information regarding the history and current situation of food security in the North explained the reasoning behind the formation of the nutrition program. The formal program goal of NNCimproving the accessibility and affordability of healthy foods in isolated Northern communities without year-round marine or surface transport-provided a critical reference point, against which I assessed the program's components to determine whether or not they were capable of producing the desired outcome. The components I focused on included the community eligibility target, subsidy design, and program implementation. A thorough understanding of the program components provided the foundation necessary to determine the internal consistency of NNC, or in other words, how well the components of the program supported and aligned with each other. Internal consistency is essential to generating and properly implementing a clear plan of action and design (Brigham, Power, \& Hunter, 2002). Any inconsistencies within the program contributed to the overall process evaluation.

\section{Results}

\section{Background of Northern Food Insecurity}

The formation of a subsidized nutrition program in the North was a response to high rates of food insecurity in Canada's Northern communities. Standing Committee on Aboriginal Affairs and Northern Development (2011) defines food insecurity as "the inability to acquire or consume an adequate quality or sufficient quantity of food in socially acceptable ways or the uncertainty that one will be able to do so" (p. vii).

Canada's Northern communities face multiple barriers to maintaining food security, including geographic location and the consequences of colonization. Today, expensive store-bought foods are offered to a population with comparatively low average incomes, while climatic patterns and geographic location create challenges for local agricultural producers. Encouraging reliance on subsistence hunting faces its own challenges, including concern over contaminants (mercury, persistent organic pollutants, etc.) in the animals, decreased affordability of hunting equipment and fuel, or just a lost taste for country food. Loss of traditional knowledge of hunting, gathering and preparing country foods in Aboriginal families also presents a barrier to maintaining food security (Mirella \& Nelson, 2012). Intensifying these issues are the high rates of poverty, limited educational attainment, and high rates of unemployment prevalent in many of these isolated communities (Indigenous and Northern Affairs Canada [INAC], 2013). High rates of gambling and substance addictions also compromise the overall health and wellbeing of Northern communities (INAC, 2013). These current issues stem from a long history of cultural, political, and social disparities, and combine to create inadequate and uncertain access to acceptable amounts and quality of healthy food within isolated Northern communities.

To gain a better understanding of food insecurity, International Polar Year Invit Health Survey conducted a survey among Inuit people in the Canadian Arctic from 2007 to 2008 . The results show that $62.6 \%$ of the 1,901 Invit households surveyed experience food insecurity (Council of Canadian Academies, 2014). Although this number is limited to Inuit households in the North, it can provide a rough comparison to the 2008 Canadian Community Survey that reported which only $11.3 \%$ of households in all of Canada experience some level of food security (Council of Canadian Academies, 2014). The difference in numbers indicates the likelihood of Northern communities to 
experience greater food insecurity, and the need for strong implementation of the NNC program to help make healthy food more accessible to Northern communities.

\section{Formation of NNC Program}

The NNC program evolved from an existing transport subsidy program known as Food Mail Service (FMS). Created in the 1960s, the FMS was intended to reduce high shipping costs to the North for various goods. These goods included perishable and non-perishable food, hunting equipment, medical supplies, prescription drugs, and other select household or basic goods, such as diapers and cleaning supplies (SCAAND, 2011). The subsidy was directed to air carriers, to reduce the cost of shipping and to allow retailers, individuals, healthcare institutions, and restaurants the freedom to order various types of foods to satisfy specific dietary needs (SCAAND, 2011).

Concerns developed as program costs of the FMS increased yearly, largely due to rising fuel costs and higher service demand (SCAAND, 2011). A comprehensive review of the program, released in 2009, resulted in a transition to the Nutrition North Canada (NNC) program in 2011 (De Schutter, 2012; SCAAND, 2011). NNC revised the list of eligible items, creating two tiers of perishable food items and basing the division on nutritional value (Government of Canada, 2013). The higher subsidy covers fresh and frozen foods such as vegetables and fruit, bread, milk, meat, and eggs. The lower subsidy covers items such as flour, crackers, ice cream, and pre-prepared meals, including pizza and lasagna. The subsidy rates vary across different communities, depending on various factors such as shipping costs and number of program participants. Nonperishable items such as canned foods, diapers, and hunting equipment are no longer subsidized (Government of Canada, 2013). The NNC also shifted subsidies from transportation companies to Northern retailers (SCAAND, 2011). This change gave the responsibility of adjusting food prices to reflect subsidization to individual store owners.

\section{Program Components of NNC}

The overall objective of the NNC program is to improve the accessibility to and affordability of healthy foods in Northern communities that do not have year-round marine or road access (Galloway, 2014; De Schutter, 2012; INAC, 2013; Government of Canada, 2013; Auditor General of Canada, 2014). Two federal departments, Indigenous and Northern Affairs Canada (INAC) and Health Canada, share specific responsibilities in implementing the NNC program. INAC provides, monitors, and verifies the subsidies for eligible foods and promotes program awareness, outreach, and engagement. Health Canada oversees the implementation of community-based nutrition education initiatives and provides support for overall program implementation (INAC, 2014). Other key stakeholders of the NNC program include Northern retailers, Southern suppliers and country food processors, Aboriginal communities and organizations, and Northerners living in eligible communities (INAC, 2014).

A fixed budget of $\$ 60$ million in program funding is subdivided each year to provide $\$ 53.9$ million towards the subsidy component, $\$ 3.4$ million in program operations, and \$2.9 million to Health Canada's nutrition education initiatives (INAC, 2013). In November 2014, the federal government announced a budget increase of $\$ 11.3$ million, with a $5 \%$ annual compound escalator to keep pace with growing demands for program services (Government of Canada, 2014).

INAC pays the subsidy directly to registered Northern retailers, Southern suppliers, and country food processors, based on the weight of eligible items shipped to the community. The recipients of the subsidy are required to pass it on to customers by reducing the price of eligible food products (Government of Canada, 2013). A claims processing system is run by an independent company contracted by INAC to ensure that the retailers are passing on the full subsidy to the consumers.

\section{Problem Areas}

Carrying out a process evaluation on NNC reveals certain incongruities within the program design. I have found that the definition of eligible communities, which sets boundaries on the number of potential program participants, fits poorly with the NNC's stated goal of making healthy food more accessible and affordable for Northern communities without year-round marine or ground access (INAC, 2014). Specifically, the defined program target limits the eligibility of communities based on two characteristics. The first characteristic requires that the participating community must lack year-round surface and/or marine access, and the second criteria requires that the community had previously used the FMS at the time of the program's existence (Government of Canada, 2013). The second requirement is particularly problematic because it bases eligibility on past use, rather than current need. As communities develop and change over time, accessibility to and need for affordable food may also change. Therefore, communities that did not need the program more than five years ago may be struggling to secure affordable food for their families today. The result is that the program target does not increase the accessibility to and affordability of nutritious food for all isolated Northern communities who lack year-round marine or surface access, as the program goal expresses. This internal inconsistency between goals and eligibility criteria makes it impossible for the program to achieve its intended outcomes. 
In addition to community eligibility criteria, the level of subsidy (full or partial) for each community is based on past use of the FMS. The communities must have used the FMS extensively in order to receive the full subsidy for the current NNC program. The threshold for the full subsidy requires communities to have previously received over $15,000 \mathrm{~kg} /$ year of perishable food items or more than $\$ 4$ a month per resident in transport subsidies. There are currently 84 communities receiving the full subsidy. All the communities that did not use the past services to this degree are only eligible for a partial subsidy, covering an additional 19 communities. However, the communities that received less than $100 \mathrm{~kg} / \mathrm{year}$ of perishable food items under the previous program, or did not use the program at all, are not eligible for the NNC program. As a result, 30 flyin communities that were served under the FMS are no longer eligible to receive benefits from the current NNC program (INAC, 2013). Although 103 communities are currently eligible for the program, this number does not encompass all isolated Northern communities lacking yearround surface or ground access, which the program goal specifies will be reached.

A third point on program components of NNC involves the structure of the subsidy transfer. According to the program's design, retailers are required to pass on the full subsidy for eligible items to the consumer by reducing food prices accordingly. To hold the retailers accountable for passing on the subsidy, each year, INAC requires a sample of retailers to submit a compliance report consisting of information on the types and amounts of eligible food items shipped by plane each month. However, the reports do not contain the proper documents necessary to ensure retailers are actually reducing the prices of eligible foods and passing on the full subsidy to consumers (Auditor General of Canada, 2014). The actual freight costs to retailers are not disclosed in the reports sent back to INAC (Galloway, 2014), in addition to information regarding profit margins (Auditor General of Canada, 2014). The inability for the NNC program to verify whether the full subsidy is passed onto consumers means that the Northern communities eligible for the NNC program may not even be receiving the full benefit of price-reduced nutritious food. A bad participant perception is also formed if the consumers cannot trust that the retailers are actually passing the full subsidy to them for the healthy foods that they purchase. This is a major weakness in program implementation, transparency, and reliability.

\section{Discussion}

\section{Recommendations}

For the program to be successful, the program target needs to be consistent with the community eligibility criteria. The eligibility criteria should be adjusted to capture the complete goal of ensuring nutritious food is more accessible and affordable to all isolated Northern communities without year-round marine or ground access. By changing the eligibility basis to current need rather than past use of programming, the NNC program will have greater success in reaching its desired outcome. In order to do this, the second eligibility criteria basing eligibility on past use of the FMS should be removed. The eligibility criteria would then include all isolated Northern communities that lack year-round surface and marine access. The change in eligibility criteria resonates with the program goal, and in turn, the internal consistency of the program increases. The Implementation Evaluation Report released in September 2013 states that the community eligibility will be reviewed by the Assistant Deputy Minister of the Northern Affairs Organization, with a planned implementation and completion date of March 2014 (INAC, 2014). However, information has not been released regarding a change to the eligibility criteria.

In addition to changing eligibility criteria to match the program's target, the subsidy rates for each community should be reevaluated. The subsidy also needs to be based on current need rather than on the degree of past use of the Food Mail Service. Levels of subsidy should be allocated to each community based only on differences in operational and transportation costs. The communities with higher costs associated with shipping eligible food items would receive a greater compensation subsidy to maintain relatively consistent food costs across Northern Canada. This would create a stronger consistency of subsidies amongst isolated Northern communities and would increase the quality and design of the program. The 2013 Implementation Evaluation Report indicated that INAC was expected to re-assess community eligibility in 2012-2013 to determine whether any of the communities on partial subsidy should be on full subsidy and whether the 30 communities currently receiving no subsidy should remain so (INAC, 2013). There is no information stating that this action has been completed.

Lastly, a stronger implementation plan for the enforcement and reporting of the subsidy transfer from the retailers should be enabled. One way of achieving this is by requiring a report from the retailers that includes the cost of transportation, the number of units shipped, and a breakdown of the subsidy equated to each food item, including profit margins. It is necessary that proper program design and suitable tools are used to deliver the program to the consumers and maintain transparency and communication of program outcomes. A stronger reporting mechanism would increase the strength of the program design and ensure that the program implementation is capable of reaching the designed program outcomes. According to the Performance Strategy Report released in 
2014, the NNC program is currently undergoing reviews to adjust the review process, however, further information has not yet been released (INAC, 2014).

\section{Limitations}

As mentioned in the results section, government documents have not been recently updated to show current reviews of the NNC program. Accordingly, the criticisms offered of NNC may be based on an understanding of program components that no longer applies. In addition, the recent election of the Liberal party to a majority government may result in a change of policy or program objectives and components. The mandate letters to both Dr. Philpott (Minister of Health) and Dr. Bennett (Minister of INAC) outline a key priority of working together to update and expand the NNC program in consultation with Northern communities (Office of the Prime Minister, n.d. a, Office of the Prime Minister, n.d. b).

My research was founded on secondary sources available to the public. Although these materials were carefully reviewed and analyzed, the results will not be as strong as if they included updated information from primary sources, or materials only accessible through Access to Information requests.

The process evaluation only looks at internal components of the program and does not take into consideration the actual outcomes that are achieved. This limits the overall evaluation of the NNC program and we do not get a full picture of how the program is performing.

During the evaluation, I focused primarily on program components and their logistics. This limits the understanding of the cultural suitability of the program components for those who are using the program.

\section{Further Research}

An outcome evaluation should be conducted on the NNC program to determine how it is performing in individual communities and as a whole. The combined evaluations would provide a more complete picture of how NNC works and where there may be gaps in the program components and implementation.

Another important area for future research is to look at cultural considerations, to determine whether the food items on the NNC program's subsidy list are adequately chosen or necessary for the people in the North consuming them. Items like fresh lettuce and oranges were not part of the traditional diet of the majority of people living up North. Perhaps instead of subsidizing a selected listed of eligible foods, research needs to look at the effectiveness of subsidizing hunting equipment and healthy foods selected through collaborative input of the Northerners consuming them. Another area of research may look into subsidizing greenhouse construction and maintenance, to determine whether this is more economical and sustainable than subsidizing fly-in produce foods if fresh produce is a product sought by Northerners.

\section{Conclusion}

High costs of food are a contributing factor to food insecurity in Canada's North. Although the Nutrition North Canada program aims to make nutritious food more affordable in isolated communities, a process evaluation of the program shows weaknesses in the program design. Process evaluation takes a comprehensive approach to program evaluation and helps to develop and improve a program (Dehar et al, 1993). By assessing the program components of the NNC program, it was found that the target population is not consistent with the program goal. Furthermore, the subsidy level allocation per community and the process of the subsidy transfer from the retailer to the consumer are not sufficiently designed. These are examples of implementation failure. Process evaluation helps to differentiate between implementation failure and program failure. However, with implementation failure, the program itself may still be successful if the program components are better aligned with the goals (Harachi et al, 1999). The internal inconsistency between community eligibility and program target, subsidy levels, and weak compliance reports compromise the effectiveness of reaching $N N^{\prime}$ 's intended goals. By understanding the program components and the areas of insufficient program design, potential solutions can be drawn to strengthen the design and internal consistency between program goals, population target, and implementation.

Food insecurity is an important issue within Canada that needs a strong program design and implementation strategy to ensure that Canadians can lead healthy lives without the concern of securing a healthy diet on a day-today basis. Food insecurity contributes to malnutrition, poor learning outcomes, developmental delays, low birth weights, depression, anxiety, and suicide (Socha, Zahaf, Chambers, Abraham, \& Fiddler, 2012). These consequences can be mitigated by implementing the provided solutions, to ensure the NNC program design is of sufficient quality and availability to reduce food insecurity in Canada's North.

\section{Acknowledgements}

Special thanks to my course instructor, Cody Sharpe for the significant amount of time put in to providing feedback, guidance, and support to further this paper. 


\section{References}

Auditor General of Canada. (2014). Chapter 6-Nutrition North Canada-Aboriginal Affairs and Northern Development Canada. In 2014 Fall Report of the Auditor General of Canada. Retrieved from http://www.oag-

bvg.gc.ca/internet/English/att_e_39985. html

Brigham, C. A., Power, A. G., \& Hunter, A. (2002). Evaluating the internal consistency of recovery plans for federally endangered species. Ecological Applications, 12(3), 648-654. Retrieved from http://www.esajournals.org/doi/abs/10.1890/10510761\%282002\%29012\%5Bo648\%3AETICOR\%5D2. o.CO\%3B2?journalCode=ecap

Canada. Parliament. House of Commons. Standing Committee on Aboriginal Affairs and Northern Development. (2011). From Food Mail to Nutrition North Canada. 4th Report. 4oth Parliament, 3rd Session. Available http://foodsecurecanada.org/sites/ default/files/nnc_aano_report_4-e.pdf

Council of Canadian Academies. (2014). Aboriginal Food Security in Northern Canada: An Assessment of the State of Knowledge. Ottawa, ON: The Expert Panel on the State of Knowledge of Food Security in Northern Canada, Council of Canadian Academies. Retrieved from http://www.scienceadvice.ca/uploads/eng/assessm ents\%2oand\%2opublications\%2oand\%2onews\%2 oreleases/food\%2osecurity/foodsecurity_fullreport en.pdf

Dehar, M. A., Casswell, S., \& Duignan, P. (1993). Formative and process evaluation of health promotion and disease prevention programs. Evaluation Review, 17(2), 204-220. doi: 10.1177/0193841X9301700205

De Schutter, O. (2012). Special Rapporteur on the right to food: Visit to Canada from 6 to 16 May 2012. Office of the High Commissioner for Human Rights. Retrieved from http://www.ohchr.org/EN/NewsEvents/Pages/Displ ayNews.aspx?NewsID=12159\&LangID=E
Galloway, T. (October 2014). Is the Nutrition North Canada retail subsidy program meeting the goal of making nutritious and perishable food more accessible and affordable in the North? Canadian Journal of Public Health, 105(5), 395-397. Retrieved from http://journal.cpha.ca/index.php/cjph/article/view/4 624

Government of Canada. (2013). Fact Sheet: The Nutrition North Canada Program. Retrieved from http://www.nutritionNorthcanada.gc.ca/eng/13679 $32314461 / 1367932387670$

Government of Canada. Aboriginal Affairs and Northern Development Sector. (2014). Harper government announces additional funding for nutrition in the North [Press release]. Retrieved from http://news.gc.ca/web/article-en.do?nid=907069

Harachi, T. W., Abbott, R. D., Catalano, R. F., Haggerty, K. P., \& Fleming, C. B. (1999). Opening the black box: Using process evaluation measures to assess implementation and theory building. American Journal of Community Psychology, 27(5), 711-731. Retrieved from: http://course.zjnu.cn/kcjx/uploadfile/20081022205 86145.pdf

Indigenous and Northern Affairs Canada. Evaluation, Performance Measurement and Review Branch. (2013). Implementation Evaluation of the Nutrition North Canada Program. Project Number: 15707/12023. Final Report. Retrieved from: http://www.aadncaandc.gc.ca/eng/1395347953550/1395348287432

Indigenous and Northern Affairs Canada. Northern Affairs Organization and First Nations and Inuit Health Sectors. (2014). Performance Measurement Strategy-4.1.2 Nutrition North Canada. Retrieved from: http://www.aadncaandc.gc.ca/eng/1416929989252/1416930028365

Mirella, L. S., \& Nelson, C. H. (2012). Understanding traditional food behaviour and food security in rural First Nation communities: Implications for food policy. Journal of Rural and Community Development, 7(3), 65-82. Retrieved from http://www.jrcd.ca/viewarticle.php?id=670

Office of the Prime Minister. (n.d.a). Minister of Health Mandate Letter. Ottawa, Canada. Retrieved from http://pm.gc.ca/eng/minister-health-mandateletter 
Office of the Prime Minister. (n.d.b). Minister of Indigenous and Northern Affairs Mandate Letter. Ottawa, Canada. Retrieved from http://pm.gc.ca/eng/minister-indigenous-andNorthern-affairs-mandate-letter

Socha, T., Zahaf, M., Chambers, L., Abraham, R., \& Fiddler, T. (2012). Food security in a northern First Nations community: An exploratory study on food availability and accessibility. Journal of Aboriginal Health, 8, 5-14. Retrieved from http://www.naho.ca/jah/english/jaho8_02/08_02_f ood-security.pdf 
